\title{
Radioresistance of granulation tissue-derived cells from skin wounds combined with total body irradiation
}

\author{
TINGYU DAI, ZELIN CHEN, LI TAN and CHUNMENG SHI \\ Institute of Combined Injury, State Key Laboratory of Trauma, Burns and Combined Injury, \\ Chongqing Engineering Research Center for Nanomedicine, College of Preventive \\ Medicine, Third Military Medical University, Chongqing 400038, P.R. China
}

Received April 7, 2015; Accepted February 2, 2016

DOI: $10.3892 / \mathrm{mmr} .2016 .4939$

\begin{abstract}
Combined radiation and wound injury (CRWI) occurs following nuclear explosions and accidents, radiological or nuclear terrorism, and radiation therapy combined with surgery. CRWI is complicated and more difficult to heal than single injuries. Stem cell-based therapy is a promising treatment strategy for CRWI, however, sourcing stem cells remains a challenge. In the present study, the granulation tissue-derived cells (GTCs) from the skin wounds (SWs) of CRWI mice (C-GTCs) demonstrated a higher radioresistance to the damage caused by combined injury, and were easier to isolate and harvest when compared with bone marrow-derived mesenchymal stromal cells (BMSCs). Furthermore, the C-GTCs exhibited similar stem cell-associated properties, such as self-renewal and multilineage differentiation capacity, when compared with neonatal dermal stromal cells (DSCs) and GTCs from unirradiated SWs. Granulation tissue, which is easy to access, may present as an optimal autologous source of stem/progenitor cells for therapeutic applications in CRWI.
\end{abstract}

\section{Introduction}

Combined radiation and wound injury (CRWI) is characterized as radiation injury coupled with wounds, and is expected to occur following nuclear explosions and accidents, radiological or nuclear terrorism, and radiation therapy in combination with surgery or other modalities (1). Wound healing is a complicated process, and exposure to radiation may significantly aggravate the degree of damage and prolong healing time $(2,3)$. Currently,

Correspondence to: Professor Chunmeng Shi, Institute of Combined Injury, State Key Laboratory of Trauma, Burns and Combined Injury, Chongqing Engineering Research Center for Nanomedicine, College of Preventive Medicine, Third Military Medical University, 30 Gaotanyan Street, Chongqing 400038, P.R. China

E-mail:shicm@sina.com

Key words: combined radiation and wound injury, granulation tissue, stem cells, radioresistance there is no effective medical countermeasure for the management of CRWI.Emerging stem cell-based therapy is considered to be promising for the treatment of CRWI; however, the cell source remains a challenging issue (4). Among various stem cell populations, bone marrow-derived mesenchymal stromal cells (BMSCs) are commonly applied in experimental models and clinical trials (5-8). However, the lymphohematopoietic system is particularly sensitive and vulnerable to radiation exposure (9), which indicates that bone marrow is not a good source for autologous cell therapy in CRWI, and there is an urgent requirement to develop alternative cell sources.

Skin is the largest organ in the body and during the past decade the importance of the dermis as an easily accessible source of stem cell populations, and their promising significance in wound repair and other diseases has been established (10-12). Recently, the granulation tissue-derived cells (GTCs) were further characterized as an abundant cell source for their important therapeutic efficacy in wound healing and tissue repair (13). As skin is relatively insensitive to radiation, the present study hypothesized that the GTCs from CRWI may represent an alternative source of adult stem cells for transplantation. The aim of the present study was to investigate the biological features of GTCs from the skin wounds (SWs) of CRWI mice (C-GTCs). Multiple biological characteristics, including the radiation sensitivity of C-GTCs, were investigated and compared with BMSCs from CRWI mice, dermal stem cells (DSCs) from neonatal C57BL/6 mice and GTCs from unirradiated SWs.

\section{Materials and methods}

Animals and wound model. A total of 14 female C57/BL mice (age, 6 weeks; weight, 20-22 g) were purchased from the Center of Experimental Animals at the Third Military Medical University (Chongqing, China). The mice were randomly divided into two groups (7 mice/group): CRWI group and SW group. Neonatal mice (age, 1 day) were raised and used for neonatal DSC isolation.

Total-body irradiation was delivered at a rate of $0.70 \mathrm{~Gy} / \mathrm{min}$ from a ${ }^{60} \mathrm{Co}$ gamma-ray source at the Radiation Center of the Third Military Medical University. The mice from the CRWI group were exposed to a total of $6 \mathrm{~Gy}$ in a single dose, and an SW was created $30 \mathrm{~min}$ after irradiation. In each group, the 
SW was implemented as described previously (14). The mice were anaesthetized by intraperitoneal injection with $1 \%$ pentobarbital (30 mg/kg; Merck Millipore, Darmstadt, Germany) and the back hair was shaved. A circular, full-thickness SW $(\sim 1.5 \mathrm{~cm}$ in diameter) was made in the center of the back using sterilized ophthalmic scissors and forceps following disinfection of the mouse skin with iodophor (Jinshan Co., Ltd., Chengdu, China). The mice were group-housed under standard conditions throughout the study, under a 12-h light/dark cycle with ad libitum access to food and water. All procedures on the mice were approved by the ethics committee of the Third Military Medical University.

Cell isolation and culture. To obtain GTCs from the CRWI and SW mice, the mice were sacrificed by cervical dislocation 7 days after the SW was created and the granulation tissues were acquired. The tissues were washed twice with $75 \%$ ethanol and phosphate-buffered saline (PBS) and sliced into small sections $\left(\sim 1 \mathrm{~mm}^{3}\right)$. The sections were digested with $0.25 \%$ collagenase I (Worthington Biochemical Corp., Lakewood, NJ, USA) and the cells were agitated into cell suspension for $2 \mathrm{~h}$ at $37^{\circ} \mathrm{C}$, then cultured in Iscove's modified Dulbecco's medium (IMDM; GE Healthcare Life Sciences, Logan, UT, USA) supplemented with Gibco $10 \%$ fetal bovine serum (FBS; Thermo Fisher Scientifc, Inc., Waltham, MA, USA), $1 \%$ penicillin/streptomycin $(1 \mathrm{ml} / 100 \mathrm{ml}$; Beyotime Institute of Biotechnology, Shanghai, China) at $37^{\circ} \mathrm{C}$ under an atmosphere of $5 \% \mathrm{CO}_{2}$.

BMSCs were obtained from the femurs and tibiae of CRWI mice. The cells were flushed out using a $1 \mathrm{ml}$ syringe and filtered with a 200 Mesh CellCribble (Sangon Biotech Co., Ltd., Shanghai, China). A single-cell suspension was created as described above.

To obtain DSCs, isolation was performed as described previously (15). Full-thickness skin tissue was obtained from four neonatal C57BL/6 mice (age, 1 day), according to a previous study (16). The tissue was washed in $75 \%$ ethanol and PBS and the subcutaneous tissue was removed. The skin tissue was sliced into small sections $\left(\sim 4 \mathrm{~mm}^{2}\right)$, transferred to $0.25 \%$ trypsin (HyClone; GE Healthcare Life Sciences) and digested overnight at $4^{\circ} \mathrm{C}$. The epidermis was discarded and the dermal layer was sliced into smaller sections $\left(\sim 0.5 \mathrm{~mm}^{2}\right)$. The tissue sections were flushed into a cell suspension and cultured as described above. Passage 0-3 cells were used in the further experiments.

Cell attachment and proliferation. To investigate cell adhesion, a cell attachment assay was performed as described previously (17). Resuspended cells from the different populations were seeded into 24 -well plates at a density of $1.0 \times 10^{4}$ cells/well. At $0.5,1,2$ and $4 \mathrm{~h}$ after inoculation, the cells were washed twice with PBS, fixed with $4 \%$ paraformaldehyde (Wuhan Boster Biological Technology, Ltd., Wuhan, China) and stained with DAPI (Beyotime Institute of Biotechnology) for $10 \mathrm{~min}$. The cell number in 10 randomly selected fields was counted under a fluorescence microscope (BX51TRF; Olympus Corporation, Tokyo, Japan) and cell adhesion was presented as the mean cell number. A cell proliferation assay was performed as described previously (18). Cells were seeded in 96-well plates at a density of 3,000 cells/well and cultured at $37^{\circ} \mathrm{C}$. At $0,1,2,3,4$ and 5 days after seeding, the media was replaced with $100 \mu$ l PBS and $10 \mu \mathrm{l}$ Cell Counting Kit-8 (CCK-8; Dojindo Molecular
Technologies, Inc., Kumamoto, Japan) for each well, and cells were incubated for another $2 \mathrm{~h}$ at $37^{\circ} \mathrm{C}$. The absorbance was measured at $450 \mathrm{~nm}$ using a Model 680 Microplate Reader (Bio-Rad Laboratories, Inc., Hercules, CA, USA).

Colony formation assay. To detect the single-cell colony formation ability of the different cell types, a colony formation assay was performed as described previously (19). Cells were plated into 6-well plates (3,000 cells/well) with IMDM supplemented with $10 \%$ FBS and cultured at $37^{\circ} \mathrm{C}$. After 12 days, cells were fixed with $4 \%$ paraformaldehyde, stained using a Wright-Giemsa staining kit (Nanjing Jiancheng Bioengineering Institute, Nanjing, China) and washed twice with distilled water. The number of colonies that contained $>50$ cells was counted and images of the colonies were randomly captured using a light microscope (CK40-F200; Olympus Corporation). The colony area was measured using ImageJ software 1.48 (NIH, Bethesda, MA, USA) and the mean area of the colonies was calculated.

Detection of senescence-associated $\beta$-galactosidase (SA- $\beta$-gal) activity. To establish the senescence state of the cells, SA- $\beta$-gal activity was determined as described previously (20). Briefly, passage 2 cells were harvested and plated into 6 -well plates $\left(1.0 \times 10^{4}\right.$ cells/well), and $24 \mathrm{~h}$ after incubation the SA- $\beta$-gal activity was detected using an SA- $\beta$-gal staining kit (C0602; Beyotime Institute of Biotechnology) according to the manufacturer's instruction. The numbers of SA- $\beta$-gal-positive and total cells in 10 randomly selected fields were counted under a light microscope (CK40-F200), and the percentage of senescent cells was displayed as the ratio of the number of SA- $\beta$-gal-positive cells to total cells.

Cell migration assay. To observe the migration ability of the cells, a scratch-wound assay was performed as described previously (21). Confluent cells were continuously scratched through the entire monolayer using a sterile P200 pipette tip (Axygen Scientific Inc., Union City, CA, USA). After washing with PBS, the wells were cultured with fresh medium at $37^{\circ} \mathrm{C}$. Images of the wounds were captured (magnification, x400) 0 , 12,24 and $36 \mathrm{~h}$ after scratching. The rate of wound closure (\%) at various points was calculated as follows: [(Original wound area - residual wound area) / original wound area] x 100.

Examination of cell differentiation. To investigate the differentiation ability of the cells, the cells were incubated in osteogenic and adipogenic differentiation media [Cyagen Biosciences (Guangzhou) Inc., Guangzhou, China]. After a 3-week incubation at $37^{\circ} \mathrm{C}$, the cells were stained with Alizarin Red (EMD Millipore, Billerica, MA, USA) and quantitative analysis of osteogenic differentiation was performed using an osteogenesis assay kit (MUBMX-90021; EMD Millipore), according to the manufacturer's instruction. For adipogenic differentiation, induced lipid droplets were visualized with Oil Red O (Sigma-Aldrich, St. Louis, MO, USA). Quantitative analyses of the lipids were performed by spectrophotometry (1510; Thermo Fisher Scientific, Inc.) of isopropanol-extracted Oil Red O staining.

Statistical analysis. All data were analyzed by SPSS 13.0 and expressed as the mean \pm standard error of the mean. Statistical 
A

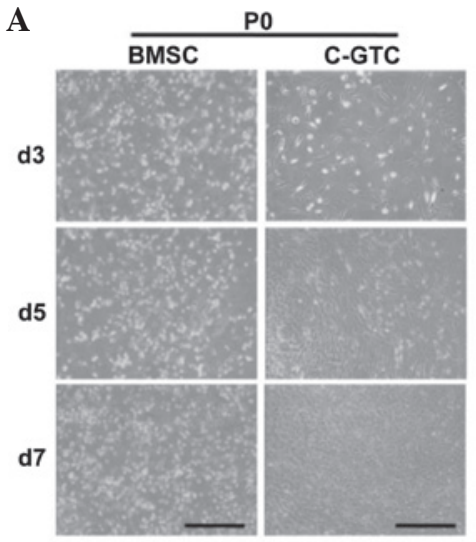

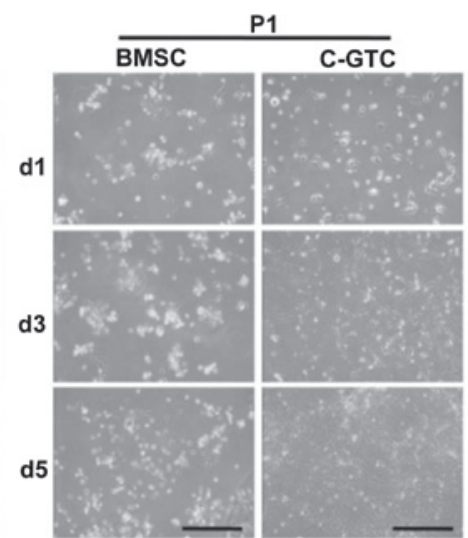

B

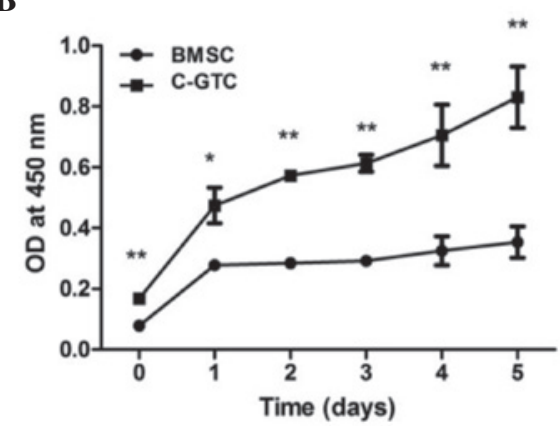

Figure 1. Comparison of proliferative capacity between C-GTCs and BMSCs in the CRWI group. (A) The growth of cells was observed at days 3,5 and 7 for P0, and at days 1, 3 and 5 for P1 (scale bar, $500 \mu \mathrm{m}$ ). (B) Quantitative analysis of C-GTCs and BMSCs using the Cell Counting Kit-8. ${ }^{*} \mathrm{P}<0.05$, ${ }^{* *} \mathrm{P}<0.01$ vs. BMSC group. BMSC, bone marrow-derived mesenchymal stromal cells; C-GTC, granulation tissue-derived cells from the skin wounds of CRWI mice; CRWI, combined radiation and wound injury; P0, primary passage; P1, subculture; d, day; OD, optical density.

A

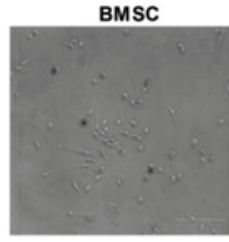

D

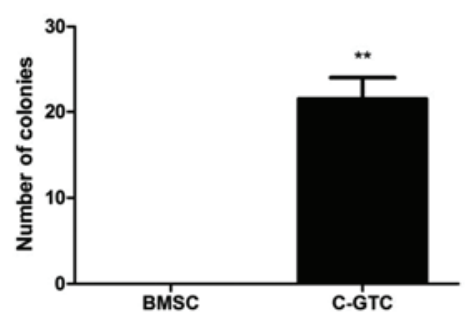

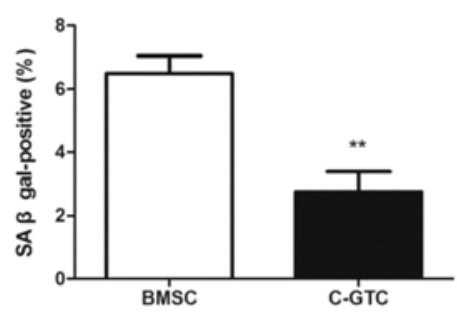

E

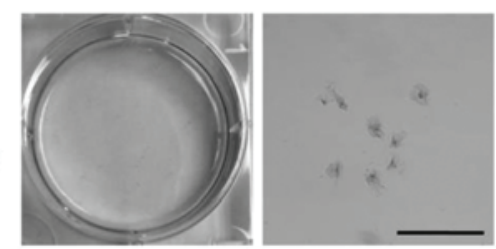

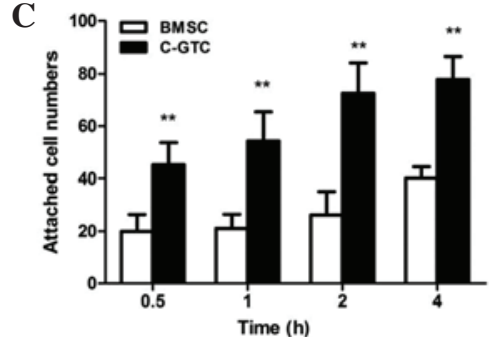

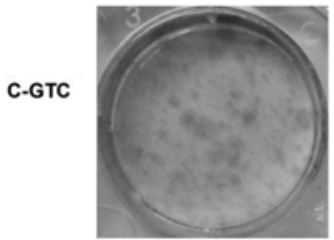

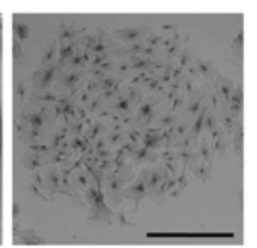

Figure 2. Senescence, adhesion and colony-formation of C-GTCs and BMSCs. (A) SA- $\beta$-gal activity analysis in which positive cells were stained blue (dark stain in the figure). (B) Percentage of SA- $\beta$-gal-positive cells in a high power field (x200) was calculated. (C) Cell adhesion assay. At the time-point of $0.5,1$, 2 and $4 \mathrm{~h}$ after plating, the cells were stained and cell attachment was measured by the number of cells per field. (D) Quantitative analysis of colony formation ability. (E) Colonies were cultured for 12 days and stained with Wright-Giemsa [left: Visual observation; right: Microscopic image (magnification, x200)]; scale bar, $500 \mu \mathrm{m} .{ }^{* *} \mathrm{P}<0.01$ vs. BMSC group. BMSC, bone marrow-derived mesenchymal stromal cells; C-GTC, granulation tissue-derived cells from the skin wounds of CRWI mice; CRWI, combined radiation and wound injury; SA- $\beta$-gal, senescence-associated $\beta$-galactosidase.

significance was examined with an independent-samples $t$ test for comparison of C-GTCs and BMSCs from mice with CRWI, and by one-way analysis of variance for multiple comparisons. $\mathrm{P}<0.05$ was considered to indicate a statistically significant difference.

\section{Results}

C-GTCs and BMSCs exhibit different sensitivities to radiation. The proliferative capacity of BMSCs and C-GTCs derived from mice with CRWI were compared. The primary passage (P0) C-GTCs demonstrated comparable proliferation ability following subculture (P1). However, the BMSCs presented markedly inhibited growth following subculture (Fig. 1A). To further determine the difference, the proliferative ability of the $\mathrm{P} 1$ of the two populations was examined; the result indicated marked growth suppression in the BMSCs (Fig. 1B). Furthermore, the biomarker, SA- $\beta$-gal was used to evaluate cellular senescence $24 \mathrm{~h}$ after incubation. A higher percentage of blue-stained BMSCs was detected (Fig. 2A and B), indicating a greater quantity of aging cells in BMSCs. These experiments indicate that the BMSCs exhibited a higher sensitivity to damage by CRWI.

To further elucidate the biological characteristics of C-GTCs and BMSCs, the cell adherence and colony formation abilities were evaluated. C-GTCs and BMSCs adhered to plastic surfaces; however, C-GTCs demonstrated more rapid and greater attachment than BMSCs at 30 mins after cell plating, and the significant difference persisted throughout the $4 \mathrm{~h}$ of culture (Fig. 2C). With regard to the colony forming assay, no colonies were observed in the BMSC group, while C-GTCs demonstrated a significantly enhanced colony forming capability $(\mathrm{P}<0.01$; Fig. 2D and $\mathrm{E})$.

Morphology, colony formation and proliferation of C-GTCs. C-GTCs were demonstrated to be more radioresistant and 
A
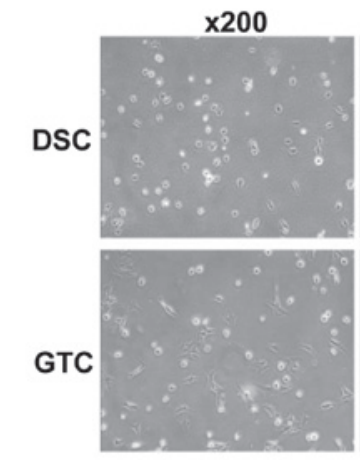

C-GTC

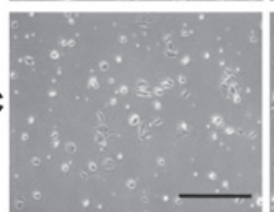

$\times 400$
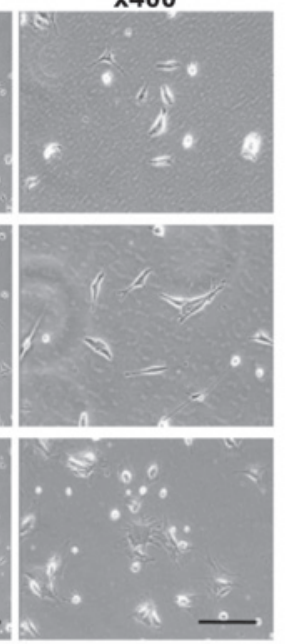

B

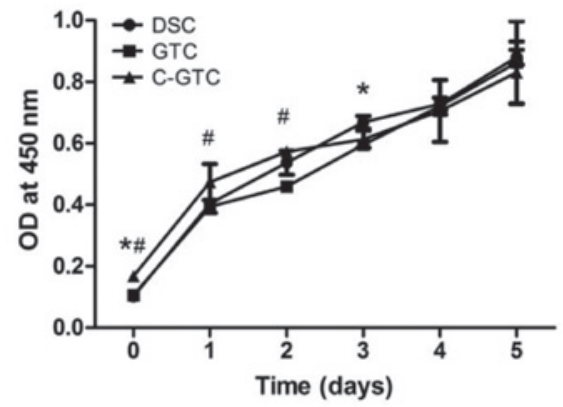

Figure 3. Morphological observation and proliferation of DSCs, GTCs and C-GTCs. (A) Unirradiated DSCs and GTCs demonstrated typical elongated, fibroblast-like morphology, however the C-GTCs exhibited a flattened phenotype. Scale bar, $500 \mu \mathrm{m}$ with magnification, $\mathrm{x} 200$; scale bar, $200 \mu \mathrm{m}$ with magnification, x400. (B) Quantitative analysis using the Cell Counting Kit-8. "P<0.05 vs. DSCs and ${ }^{\#} \mathrm{P}<0.05$ vs. GTCs. DSC, dermal stromal cells; GTC, granulation tissue-derived cells; C-GTCs, GTCs from the skin wounds of CRWI mice; CRWI, combined radiation and wound injury; OD, optical density.
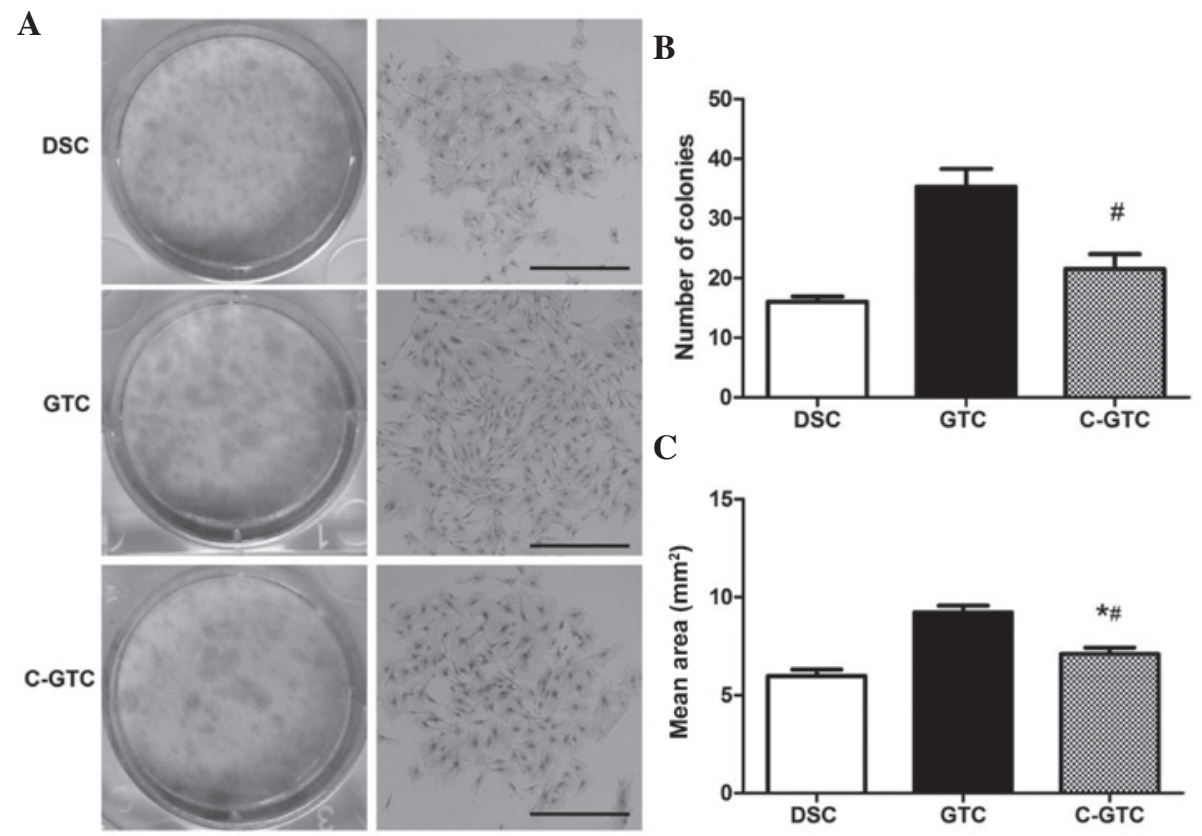

Figure 4. Colony formation assay. (A) Colonies were cultured for 12 days and stained with Wright-Giemsa [left: Visual observation; right: Microscopic images (magnification, x200); scale bar, $500 \mu \mathrm{m}]$. (B and C) Quantitative analysis of colony forming ability. ${ }^{*} \mathrm{P}<0.05$ vs. DSCs, and ${ }^{\#} \mathrm{P}<0.05$ vs. GTCs. DSC, dermal stromal cells; GTC, granulation tissue-derived cells; C-GTCs, GTCs from the skin wounds of combined radiation and wound injury mice.

easily accessible when compared with BMSCs from mice with CRWI. To further investigate the biological features of C-GTCs, neonatal DSCs and GTCs from wounds without irradiation (GTCs) were used as control cells.

The morphologies of cells from the three groups (C-GTC, GTC and DSC) were analyzed under a light microscope using unstained cells. GTCs and DSC had an elongated, fibroblast-like morphology, whereas C-GTCs were larger, irregularly-shaped and appeared flattened (Fig. 3A). The CCK-8 assay result suggested that the patterns of cell proliferation exhibited by C-GTCs, GTCs and DSCs were comparable (Fig. 3B). Furthermore, the colony forming capacity, which is a feature associated with stem cells, was determined. The colony forming experiments demonstrated that GTCs formed the most colonies, followed by C-GTCs and finally DSCs (Fig. 4). Accordingly, the mean area of the colonies from large to small was also in the order GTCs, C-GTCs and DSCs (Fig. 4).

Migration and adhesion of C-GTCs. To examine whether CRWI affects cell migration, the cell migration ability of C-GTCs were evaluated using a scratch wound assay. Images of scratch wounds were captured at $0,12,24$ and $36 \mathrm{~h}$ after treatment, and the wounds in C-GTCs, GTCs and DSCs were completely closed by $36 \mathrm{~h}$. The wound area was then quantified 
A

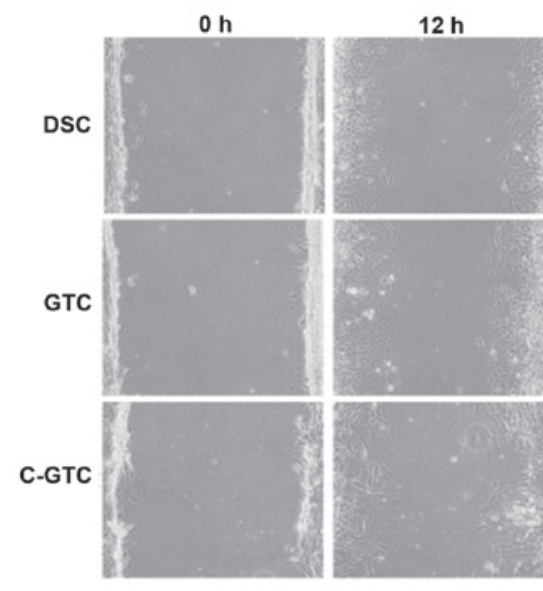

B

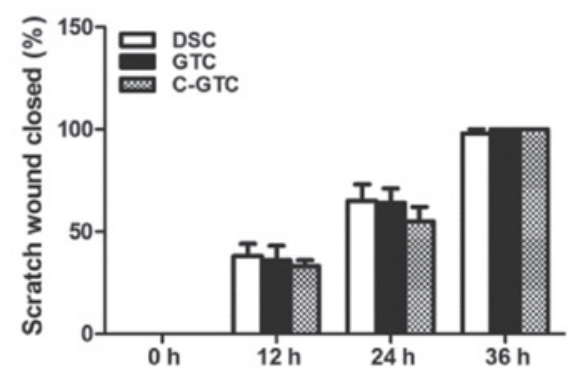

$24 \mathrm{~h}$

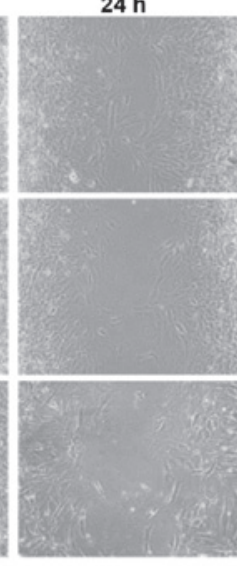

C
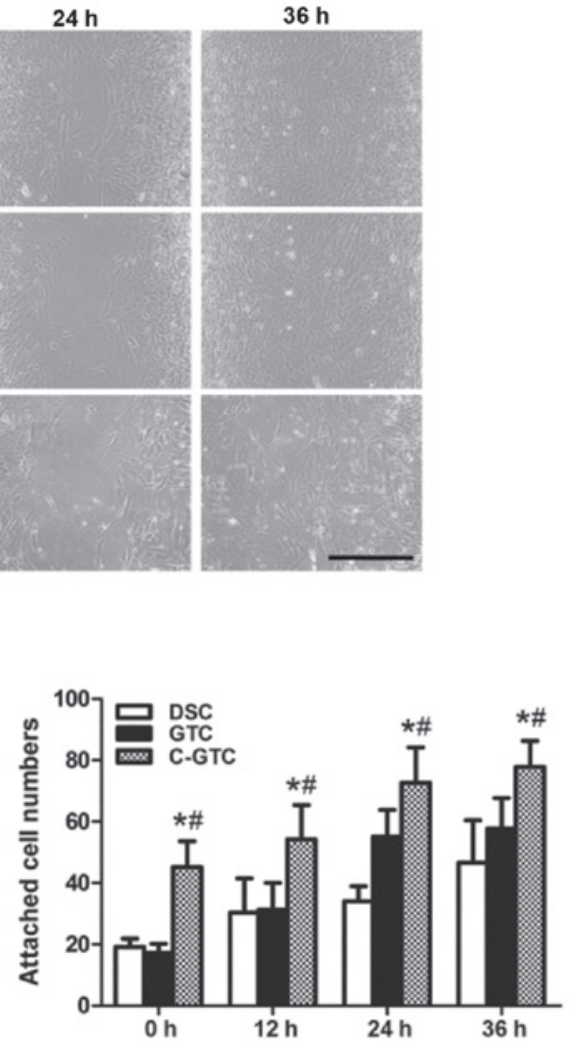

Figure 5. Cell migration and adhesion ability. (A) Images of each group were captured at 0, 12, 24 and $36 \mathrm{~h}$. Scale bar, $500 \mu \mathrm{m}$. (B) The rate of scratch wound closure compared with the primary area. (C) Quantitative analysis of the cell adhesion assay. *P<0.01 vs. DSC and ${ }^{\# P<0.01 ~ v s . ~ G T C s . ~ D S C, ~ d e r m a l ~ s t r o m a l ~}$ cells; GTC, granulation tissue-derived cells; C-GTCs, GTCs from the skin wounds of combined radiation and wound injury.

using Image $\mathbf{J}$ software and the healing rate was calculated. The data indicated that there was no significant difference in the rate of C-GTCs when compared with that of GTCs and DSCs ( $\mathrm{P}>0$ 0.05; Fig. 5A and B).

To investigate the effect of radiation on cell adhesion, equal numbers of C-GTCs, GTCs and DSCs were plated into 24-well plates and attachment was monitored over $4 \mathrm{~h}$. The result demonstrated that $\mathrm{C}-\mathrm{GTC}$ s had a marked attachment ability and exhibited processes and flattened shapes (Fig. 5C), indicating that irradiation may improve the adhesive capacity of mesenchymal stem cells (MSCs).

Differentiation potential of C-GTCs. The osteogenic and adipogenic differentiation potential is a unique characteristic of MSCs. Therefore, the differentiation capability of C-GTCs were evaluated, with DSCs and GTCs serving as controls. Fig. 6A demonstrates that C-GTCs were able to differentiate into osteocytes (with the mineralized nodules highlighted by Alizarin Red staining). However, quantitative analysis indicated that C-GTCs formed fewer mineralized extracellular matrices than GTCs $(\mathrm{P}<0.01$; Fig. 6B). In addition, when cultured in adipo-inductive media for 7 days, all three populations were able to form lipid globules; the lipid droplets were stained with Oil Red O (Fig. 6A). The results indicate that all three cell populations displayed the potential to differentiate into adipocytes, including C-GTCs, although absorbance of the Oil Red O extract was lower in the C-GTC group than those of the control groups (GTCs and DSCs; Fig. 6C). These results indicated that the differentiation ability of GTCs was not abrogated by CRWI.

\section{Discussion}

Adult stem cell-based therapy presents as a promising treatment strategy for diseases and injuries, including CRWI (22). Stem cells are isolated from different types of tissue, including bone marrow, adipose tissue, the skin and umbilical cords (23). However, the cell source is a challenge for the management of wounds that are difficult to heal, such as CRWI. In the current study, the effects of radiation on the isolation and proliferation of C-GTCs and BMSCs in mice with CRWI were investigated. Although it has been reported that BMSCs exhibit a certain quantity of radioresistance in order to retain their stem cell characteristics, including proliferation, adherence, colony formation ability and differentiation potential (24), the present results demonstrated that BMSCs were more sensitive to the damage caused by CRWI. In addition, it was particularly difficult to harvest ideal cells from the bone marrow of mice with CRWI. Notably, the isolated C-GTCs demonstrated higher resistance to CRWI and exhibited a significantly lower level of senescence when compared with BMSCs, and preserved their self-renewal and multilineage differentiation capacities as effectively as neonatal DSCs and GTCs from unirradiated SWs.

Skin is the largest organ of the body and the dermis has been shown to contain various stem cells populations (25). It has been established that stem cells are important in wound healing and that, following wounding, newly formed granulation tissue is enriched in cells that express stem cell surface markers (26). Previous studies have reported the therapeutic implications of GTCs in different animal models $(26,27)$. The 
A

Osteogenic differentiation Adipogenic differentiation
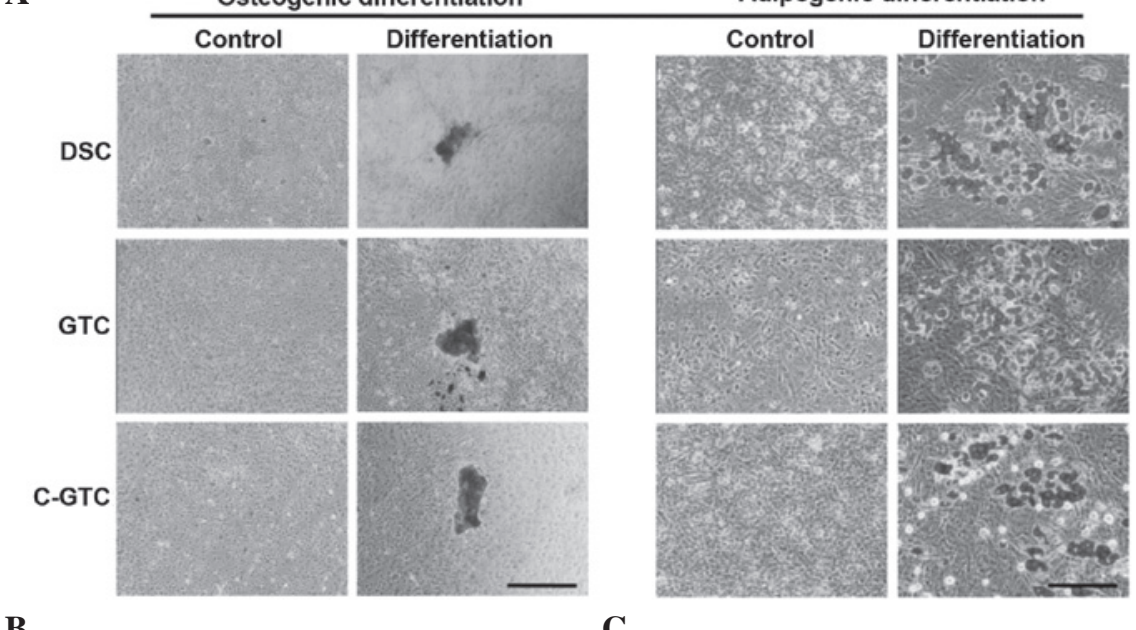

B

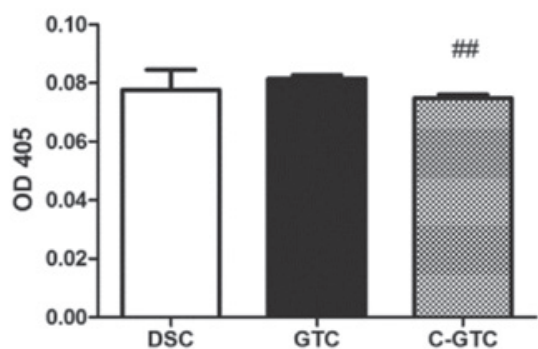

C

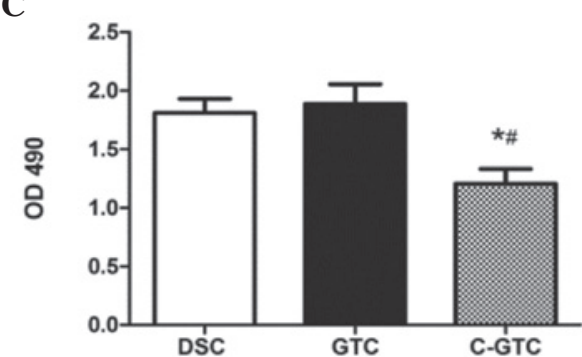

Figure 6. Osteogenic and adipogenic differentiation in DSCs, GTCs and C-GTCs. (A) Representative images of control and induced differentiated cells. Cells that underwent osteogenic differentiation were stained with Alizarin Red and cells that underwent adipogenic differentiation were stained with Oil Red O. Scale bar, $500 \mu \mathrm{m}$. Quantitative analysis of (B) mineralized nodules and (C) Oil Red O-positive staining. ${ }^{*} \mathrm{P}<0.05 \mathrm{vs}$. DSCs, ${ }^{\#} \mathrm{P}<0.05,{ }^{\# \#} \mathrm{P}<0.01 \mathrm{vs}$. GTCs. DSC, dermal stromal cells; GTC, granulation tissue-derived cells; C-GTCs, GTCs from the skin wounds of combined radiation and wound injury mice; OD, optical density.

GTCs are able to secrete important factors, such as vascular endothelial growth factor and maintain their trilineage differentiation ability in vitro (28). Furthermore, GTCs may mitigate damage and accelerate repair in liver and kidney injury $(28,29)$. Therefore, granulation tissue is emerging as a potential source of multifunctional cells for transplantation therapy.

Previous studies have demonstrated that transplantation of mesenchymal stem/stromal cells is a potent therapeutic method for radiation-induced damage in various organs and tissues, such as salivary glands (8), lungs (30), the liver $(31,32)$, skin (33), bone marrow (34) and intestines $(35,36)$. Studies have demonstrated that MSCs exert their therapeutic effects via multiple mechanisms, including engraftment and differentiation into target cell types, immunomodulation and anti-inflammation activities [by decreasing the expression levels of inflammatory cytokines, such as interleukin (IL) $-1 \alpha$, IL- $\beta$ and tumor necrosis factor- $\alpha$ ], and promoting the paracrine action of growth factors associated with neovascularization $(33,36)$. In addition, the transplantation of MSCs was reported to upregulate the expression of cell cycle-associated genes, including cyclin-dependent kinase inhibitor 1A (37). Furthermore, oxidative stress may be reduced following MSC therapy (31). In our previous study, it was reported for the first time, to the best of our knowledge, that systemic transplantation of neonatal dermal multipotent cells significantly promoted survival, and accelerated hematopoietic recovery and wound healing in rats with CRWI. This indicated that stem cell therapy achieves multiple therapeutic effects and provides a potential novel strategy for the treatment of severe traumatic injuries comprised of multiple tissue/organ damage, such as radiation combined injuries (38). In the present study, it was verified that the isolated C-GTCs possessed comparable stem cell-associated properties with neonatal DSCs and GTCs from normal wounds without irradiation. Considering the ease of accessibility, granulation tissue is proposed to be an optimal, autologous source of stem/progenitor cells for therapeutic applications in CRWI, for the replacement of skin, as well as for tissue repair of other organs.

The source of MSCs for transplantation therapy of CRWI has been widely investigated. Previous research has demonstrated that granulation tissue derived from the dermis is a promising stem cell source and that the GTCs exhibit stem cell-associated properties. In the current study, the characteristics of C-GTCs (obtained from CRWI mice) were investigated, and the C-GTCs displayed advantageous properties when compared with BMSCs, including improved radiation resistance and biological characteristics, such as proliferative, colony formation and adhesion abilities. In addition, C-GTCs better retained their stem cell characteristics when compared with DSCs and GTCs that were obtained from normal granulation tissue. In conclusion, C-GTCs have been demonstrated as a potential autologous source for the treatment of CRWI.

\section{Acknowledgements}

The present study was supported by the State Key Basic Research Development Program (grant no. 2012CB518103), the 
Natural Science Foundation Programs (grant no. 81072523), the Program of New Century Excellent Talents in University from the Ministry of Education (grant no. NCET-11-0869), the Innovation Team Building Program of Chongqing University (grant no. KJTD201338) and Intramural Research Project grants from the Third Military Medical University (grant nos. BWS13C016 and AWS14007-01).

\section{References}

1. Cheng T, Chen Z, Yan Y, Ran X, Su Y and Ai G: Experimental studies on the treatment and pathological basis of combined radiation and burn injury. Chin Med J (Engl) 115: 1763-1766, 2002.

2. Vegesna V, Withers HR, Holly FE and McBride WH: The effect of local and systemic irradiation on impairment of wound healing in mice. Radiat Res 135: 431-433, 1993.

3. Wang J, Boerma M, Fu Q and Hauer-Jensen M: Radiation responses in skin and connective tissues: Effect on wound healing and surgical outcome. Hernia 10: 502-506, 2006.

4. Zhang J, Huang X, Wang H, Liu X, Zhang T, Wang Y and Hu D: The challenges and promises of allogeneic mesenchymal stem cells for use as a cell-based therapy. Stem Cell Res Ther 6: 234, 2015.

5. Bey E, Prat M, Duhamel P, Benderitter M, Brachet M, Trompier F, Battaglini P, Ernou I, Boutin L, Gourven M, et al: Emerging therapy for improving wound repair of severe radiation burns using local bone marrow-derived stem cell administrations. Wound Repair Regen 18: 50-58, 2010.

6. Zhang J, Gong JF, Zhang W, Zhu WM and Li JS: Effects of transplanted bone marrow mesenchymal stem cells on the irradiated intestine of mice. J Biomed Sci 15: 585-594, 2008.

7. Linard C, Busson E, Holler V, Strup-Perrot C, Lacave-Lapalun JV, Lhomme B, Prat M, Devauchelle P, Sabourin JC, Simon JM, et al: Repeated autologous bone marrow-derived mesenchymal stem cell injections improve radiation-induced proctitis in pigs. Stem Cells Transl Med 2: 916-927, 2013.

8. Lim JY, Yi T, Choi JS, Jang YH, Lee S, Kim HJ, Song SU and Kim YM: Intraglandular transplantation of bone marrow-derived clonal mesenchymal stem cells for amelioration of post-irradiation salivary gland damage. Oral Oncol 49: 136-143, 2013.

9. Karkanitsa LV: Radiation damage to hematopoiesis: What do we know better? Stem Cells 15 (Suppl 2): S71-S73, 1997.

10. Chen Z, Wang Y and Shi C: Therapeutic implications of newly identified stem cell populations from the skin dermis. Cell Transplant 24: 1405-1422, 2015.

11. Perng CK, Ku HH, Chiou SH, Chen IL, Tsai FT, Yang YP, Chang KY and Kao CL: Evaluation of wound healing effect on skin-defect nude mice by using human dermis-derived mesenchymal stem cells. Transplant Proc 38: 3086-3087, 2006.

12. Zabierowski SE, Fukunaga-Kalabis M, Li L and Herlyn M: Dermis-derived stem cells: A source of epidermal melanocytes and melanoma? Pigment Cell Melanoma Res 24: 422-429, 2011.

13. Spyrou GE, Watt DA and Naylor IL: The origin and mode of fibroblast migration and proliferation in granulation tissue. $\mathrm{Br} \mathrm{J}$ Plast Surg 51: 455-461, 1998.

14. Wang T, Feng Y, Sun H, Zhang L, Hao L, Shi C, Wang J, Li R, Ran X, Su Y and Zou Z: miR-21 regulates skin wound healing by targeting multiple aspects of the healing process. Am J Pathol 181: 1911-1920, 2012.

15. Gao L, Liu F, Tan L, Liu T, Chen Z and Shi C: The immunosuppressive properties of non-cultured dermal-derived mesenchymal stromal cells and the control of graft-versus-host disease. Biomaterials 35: 3582-3588, 2014.

16. Lichti U, Anders J and Yuspa SH: Isolation and short-term culture of primary keratinocytes, hair follicle populations and dermal cells from newborn mice and keratinocytes from adult mice for in vitro analysis and for grafting to immunodeficient mice. Nat Protoc 3: 799-810, 2008.

17. Kretlow JD, Jin YQ, Liu W, Zhang WJ, Hong TH, Zhou G, Baggett LS, Mikos AG and Cao Y: Donor age and cell passage affects differentiation potential of murine bone marrow-derived stem cells. BMC Cell Biol 9: 60, 2008.

18. Peng Y, Yang J, Zhang E, Sun H, Wang Q, Wang T, Su Y and Shi C: Human positive coactivator 4 is a potential novel therapeutic target in non-small cell lung cancer. Cancer Gene Ther 19: 690-696, 2012
19. Yang H, Gao LN, An Y, Hu CH, Jin F, Zhou J, Jin Y and Chen FM: Comparison of mesenchymal stem cells derived from gingival tissue and periodontal ligament in different incubation conditions. Biomaterials 34: 7033-7047, 2013.

20. Su W, Chen Y, Zeng W, Liu W and Sun H: Involvement of Wnt signaling in the injury of murine mesenchymal stem cells exposed to X-radiation. Int J Radiat Biol 88: 635-641, 2012.

21. Smith AN, Willis E, Chan VT, Muffley LA, Isik FF, Gibran NS and Hocking AM: Mesenchymal stem cells induce dermal fibroblast responses to injury. Exp Cell Res 316: 48-54, 2010.

22. Coppes RP, van der Goot A and Lombaert IM: Stem cell therapy to reduce radiation-induced normal tissue damage. Semin Radiat Oncol 19: 112-121, 2009.

23. Klopp AH, Gupta A, Spaeth E, Andreeff M and Marini F III: Concise review: Dissecting a discrepancy in the literature: Do mesenchymal stem cells support or suppress tumor growth? Stem Cells 29: 11-19, 2011

24. Nicolay NH, Sommer E, Lopez R, Wirkner U, Trinh T, Sisombath S, Debus J, Ho AD, Saffrich R and Huber PE: Mesenchymal stem cells retain their defining stem cell characteristics after exposure to ionizing radiation. Int $\mathbf{J}$ Radiat Oncol Biol Phys 87: 1171-1178, 2013.

25. Toma JG, Akhavan M, Fernandes KJ, Barnabé-Heider F, Sadikot A, Kaplan DR and Miller FD: Isolation of multipotent adult stem cells from the dermis of mammalian skin. Nat Cell Biol 3: 778-784, 2001.

26. Diaz-Flores L Jr, Gutierrez R, Madrid JF, Varela H, Valladares F and Diaz-Flores L: Adult stem cells and repair through granulation tissue. Front Biosci (Landmark Ed) 14: 1433-1470, 2009.

27. Singh AK, Patel J, Litbarg NO, Gudehithlu KP, Sethupathi P, Arruda JA and Dunea G: Stromal cells cultured from omentum express pluripotent markers, produce high amounts of VEGF and engraft to injured sites. Cell Tissue Res 332: 81-88, 2008.

28. Patel J, Gudehithlu KP, Dunea G, Arruda JA and Singh AK: Foreign body-induced granulation tissue is a source of adult stem cells. Transl Res 155: 191-199, 2010.

29. Patel J, Pancholi N, Gudehithlu KP, Sethupathi P, Hart PD, Dunea G, Arruda JA and Singh AK: Stem cells from foreign body granulation tissue accelerate recovery from acute kidney injury. Nephrol Dial Transplant 27: 1780-1786, 2012.

30. Wang H, Yang YF, Zhao L, Xiao FJ, Zhang QW, Wen ML, Wu CT, Peng RY and Wang LS: Hepatocyte growth factor gene-modified mesenchymal stem cells reduce radiation-induced lung injury. Hum Gene Ther 24: 343-353, 2013.

31. Francois S, Mouiseddine M, Allenet-Lepage B, Voswinkel J, Douay L, Benderitter M and Chapel A: Human mesenchymal stem cells provide protection against radiation-induced liver injury by antioxidative process, vasculature protection, hepatocyte differentiation and trophic effects. Biomed Res Int 2013: 151679, 2013.

32. Mouiseddine M, François S, Souidi M and Chapel A: Intravenous human mesenchymal stem cells transplantation in NOD/SCID mice preserve liver integrity of irradiation damage. Methods Mol Biol 826: 179-188, 2012.

33. Horton JA, Hudak KE, Chung EJ, White AO, Scroggins BT, Burkeen JF and Citrin DE: Mesenchymal stem cells inhibit cutaneous radiation-induced fibrosis by suppressing chronic inflammation. Stem Cells 31: 2231-2241, 2013.

34. Yang X, Balakrishnan I, Torok-Storb B and Pillai MM: Marrow stromal cell infusion rescues hematopoiesis in lethally irradiated mice despite rapid clearance after infusion. Adv Hematol 2012: 142530, 2012.

35. Bessout R, Sémont A, Demarquay C, Charcosset A, Benderitter M and Mathieu N: Mesenchymal stem cell therapy induces glucocorticoid synthesis in colonic mucosa and suppresses radiation-activated T cells: New insights into MSC immunomodulation. Mucosal Immunol 7: 656-669, 2014.

36. Chang P, Qu Y, Liu Y, Cui S, Zhu D, Wang H and Jin X: Multi-therapeutic effects of human adipose-derived mesenchymal stem cells on radiation-induced intestinal injury. Cell Death Dis 4: e685, 2013.

37. Lange C, Brunswig-Spickenheier B, Cappallo-Obermann H, Eggert K, Gehling UM, Rudolph C, Schlegelberger B, Cornils K, Zustin J, Spiess AN and Zander AR: Radiation rescue: Mesenchymal stromal cells protect from lethal irradiation. PLoS One 6: e14486, 2011.

38. Shi C, Cheng T, Su Y, Mai Y, Qu J, Lou S, Ran X, Xu H and Luo C: Transplantation of dermal multipotent cells promotes survival and wound healing in rats with combined radiation and wound injury. Radiat Res 162: 56-63, 2004. 